\title{
Heller-Pinotti, a modified partial fundoplication associated with myotomy to treat achalasia: technical and final results from 445 patients
}

\author{
Edno Tales Bianchi, Rubens Antonio Aissar Sallum, Sergio Szachnowicz, Francisco Carlos Bernal Costa \\ Seguro, Andre Fonseca Duarte, Julio Rafael Mariano da Rocha, Ivan Cecconello
}

Departament of Gatrointestinal Surgery, Clinic Hospital, University of São Paulo, São Paulo 05403-010, Brazil.

Correspondence to: Dr. Edno Tales Bianchi, Departament of Gatrointestinal Surgery, Clinic Hospital, University of São Paulo, Rua Dr. Ovídio Pires de Campos, 225, São Paulo 05403-010, Brazil. E-mail: ednotales@gmail.com

How to cite this article: Bianchi ET, Sallum RAA, Szachnowicz S, Seguro FCBC, Duarte AF, da Rocha JRM, Cecconello I. Heller-Pinotti, a modified partial fundoplication associated with myotomy to treat achalasia: technical and final results from 445 patients. Mini-invasive Surg 2017;1:153-9.

\section{Article history: \\ Key words: \\ Achalasia, \\ fundoplication, \\ myotomy, \\ Heller-Pinotti}

Received: 27 Sep 2017

First Decision: 6 Nov 2017

Revised: 27 Nov 2017

Accepted: 30 Nov 2017

Published: 28 Dec 2017

\begin{abstract}
Aim: The need for an antireflux procedure after myotomy is no longer as controversial as it used to be. However, the choice of the best fundoplication after myotomy is still controversial. The authors present the results of laparoscopic myotomies associated with postero-latero-anterior fundoplications (Heller-Pinotti). Methods: Medical records and endoscopic findings were reviewed for achalasia patients that had submitted to the procedure following 5 years of followup. Results: In total, 445 patients were enrolled: 39 (8.7\%) presented erosive esophagitis, the Los Angeles classification being A-21, B-12, C-2 and D-4 (2 with peptic substenosis and 2 Barret); 41 (9.2\%) patients had dysphagia, 4 needed reinterventions; 49 (11\%) presented a migration of the fundoplication wrap to the thorax due to hiatal hernia, this was correlated with a higher risk of present erosive esophagitis $(P=0.047)$ and dysphagia $(P<0.001)$. Conclusion: Laparoscopy myotomy postero-latero-anterior fundoplication (Heller-Pinotti) produces a good long-term outcome for dealing with dysphagia and in terms of reflux prevention.
\end{abstract}

\section{INTRODUCTION}

Myotomy of the esophageal lower sphincter is the best way to treat achalasia. It is expected that gastro esophageal reflux occurs after this procedure because one of the mechanisms of defense against reflux is withdrawn. The incidence of postoperative reflux and related complications following open cardiomyotomy without fundoplication varies between $20 \%-32 \%^{[1,2]}$.
There is therefore a consensus that an antireflux procedure should be performed at the time of the myotomy.

The choice between a total fundoplication, anterior or posterior, has already been the subject of studies and meta-analysis in the literature, though the methods for improvement are still controversial.

Some modifications were made over time in our unit.

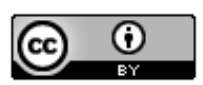

This is an open access article licensed under the terms of Creative Commons Attribution 4.0 International License (https://creativecommons.org/licenses/by/4.0/), which permits unrestricted use, distribution, and reproduction in any medium, as long as the original author is credited and the new creations are licensed under the identical terms.

For reprints contact: service@oaepublish.com

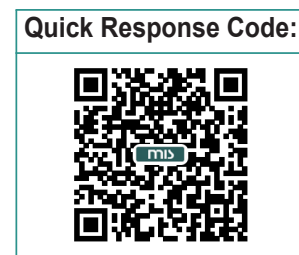




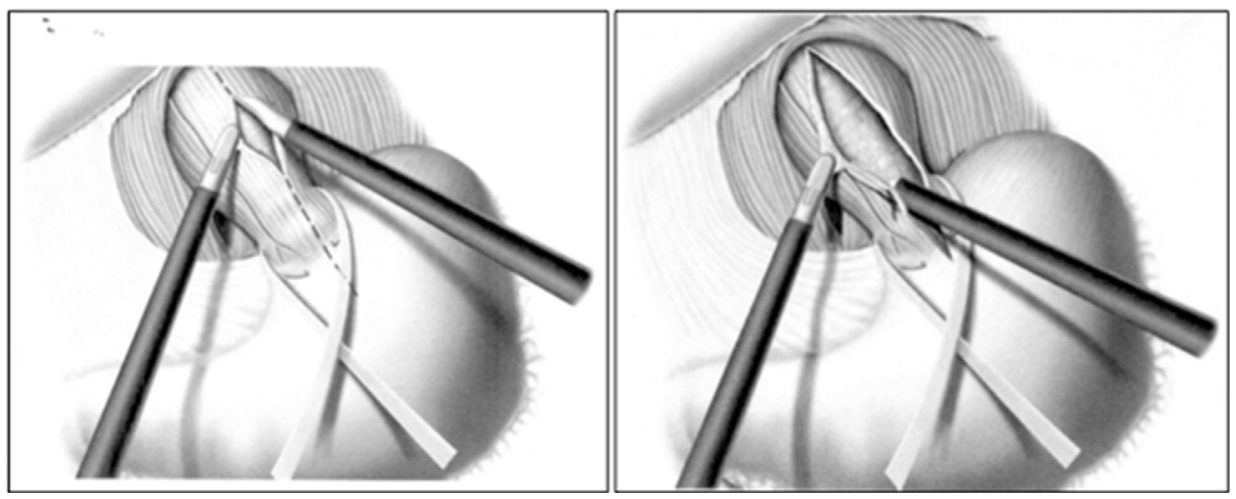

Figure 1: Laparoscopic myotomy

Pinotti et al. ${ }^{[3]}$ added a posterior suture line to the Dor fundoplication thus creating a postero-lateral-anterior fundoplication that encompassed more than the anterior fundoplication and enhanced reflux control. This type of fundoplication is widely used in Brazil and is known as the Heller-Pinotti procedure.

In this article, we demonstrate the long-term results of myotomy associated with this type of fundoplication and compare it with results from world literature.

\section{METHODS}

\section{Technique}

The arrangement of the ports for laparoscopy, as well as whether the patient is positioned with legs spread open or aligned together in the midline, is a personal choice and depends on the experience and preference of the surgeon. Our preference is to position the patient with legs spread open and the monitor positioned by the patient's head. The surgeon is positioned between the patient's legs, the first assistant is on the left side and the second assistant who is responsible for the camera, is positioned on the patient's right side.

In this position, the trocar receiving the camera is placed 3 to $5 \mathrm{~cm}$ above the umbilicus to facilitate the exposure of the gastric fundus and the hiatus. The trocar for the liver retractor is positioned in the epigastrium. In the right hypochondrium is the access to the surgeon's left hand and the portal for the right hand is in the left hypochondrium. An additional trocar can be placed into the left hypochondrium if needed.

The technical steps are as follows:

1. Mobilization of the gastric fundus: the procedure begins with the complete mobilization of the gastric fundus. It is important to divide as many short gastric vessels as possible in order to leave it free from adhesions when the fundoplication is constructed. A cause of early postoperative dysphagia is a fundoplication without a complete release of gastric fundus that results in traction and torsion of the esophagogastric junction when the stomach is distended.

2. Dissection of the esophagogastric junction: it begins with a downward movement of the stomach by an assistant and the opening of both the hepatogastric ligament and phrenoesophageal membrane preserving the hepatic branch of the vagus nerve. This allows for better traction of the distal esophagus into the abdominal cavity. The following step is the identification and dissection of the diaphragmatic pillars and separation of the esophagus from the hiatus. At this point it is important to identify the anterior and posterior vagus nerves to avoid their injury. In chagasic patients it is very common to find a twisted and dilated distal esophagus. All the adhesions of the distal esophagus in the mediastinum are released to create a safe, open area for the myotomy and to straighten the esophageal axis.

3. Cardiomyotomy: the myotomy of the distal esophagus and the cardia is performed with the surgeon's preferred instrument (hook, scissors, harmonic scalpel) by bluntly gripping and sectioning the muscle fibers, with or without force to avoid the splitting of the lower esophageal sphincter fibers. The myotomy is advanced upwards in the esophagus for a minimum length of $6 \mathrm{~cm}$ and at least $3 \mathrm{~cm}$ down in the stomach [Figure 1]. An inadvertent mucosal injury during myotomy is not uncommon, particularly at the beginning of the learning curve with the procedure. If the mucosa is opened, the defect must be closed immediately with a monofilament absorbable suture and coverage of 

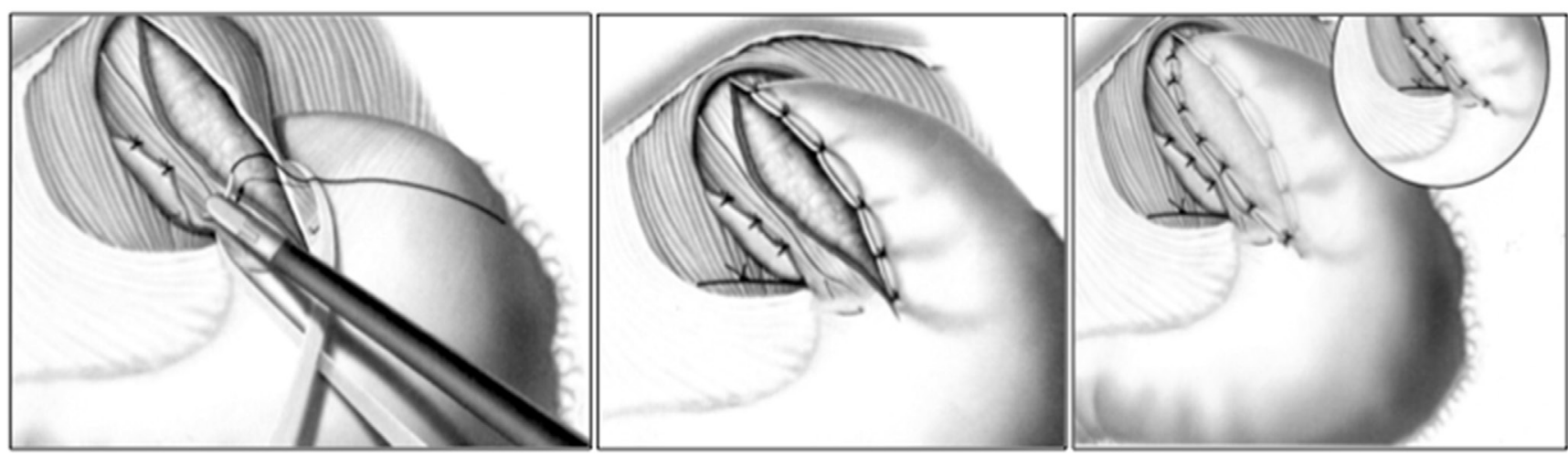

Figure 2: Laparoscopic myotomy and fundoplication

the area should be provided by the fundoplication itself. Such mishap does not increase the risk of failure of the procedure and fistula is rare.

4. Hiatoplasty: for release of the distal esophagus into the mediastinum, the hiatal defect is usually opened wide. If the defect is larger than the diameter of the esophagus, it is recommended to perform the hiatoplasty with separate stitches and approximate the second diaphragmatic.

5. Fundoplication: it is our preference to perform an anterior-lateral-posterior fundoplication with 3 suture lines between the gastric fundus and the esophagus. The 1st suture line is placed between the posterior region of the esophagus and the posterior wall of the stomach, usually with 3 to 4 stitches [Figure 2]. The second suture line is performed by joining the left lateral border of the esophageal myotomy with the gastric fundus in the transition between the anterior and posterior wall. The last suture line is placed in the right lateral border of the myotomy with the anterior face of the gastric fundus covering the entire myotomy.

\section{Patients}

Over the past several years, the 1st choice of treatment for achalasia in our institution has been the myotomy with fundoplication. Of the 849 patients submitted to laparoscopic surgery between 2000 and 2012, 445 had regular follow-ups at our hospital for more than 5 years and underwent routine upper endoscopies. The examinations were performed every 2 years, or less if the patient presented any symptoms.

\section{Data collection}

The medical records of these patients were reviewed and the following data were obtained: age, gender and follow-up time. Regarding the endoscopy examinations, it was decided to analyze the 1st examinations 5 years after the surgery, thus standardizing the endoscopic findings regarding the follow-up time. All patients were tested for serology and for the presence of Chagas disease. The etiology between chagasic and idiopathic conditions was evaluated. Presence of erosive esophagitis and complications of gastro esophageal reflux (stenosis or barret) were investigated with an endoscopy at a 5-year follow-up. It was also assessed whether fundoplications that had migrated due to hiatal hernia were intra-abdominal or intrathoracic. The seriogram was analyzed (barium swallow) before surgery to quantify the degree of dilation of the esophagus. The Rezende classification stages were used. Patients with a dilation of less than $4 \mathrm{~cm}$ were classified as in grade I, between 4 and 7 - grade II, between 7 and 10 - grade III and greater than 10 - grade IV. Patients with a dolicomegaesophagus and a degree of dilation greater than $10 \mathrm{~cm}$ were excluded from this study. The medications used by the patients were obtained from their electronic medical records. It was assessed whether a patient used a proton pump inhibitor and routinely used $20 \mathrm{mg}$ twice daily. Postoperative dysphagia was defined when the patient reported difficulty in oral intake that required some type of intervention to improve quality of life. Presence of dysphagia reported by the patient was also recorded, as well as how many years after the operation these symptoms persisted.

\section{Statistical analysis}

Calculated odds ratio and chi square between the variables.

\section{RESULTS}

Of the 445 patients, 244 were women and 201 men. The mean age was $45.6( \pm 12.7)$ years. The mean follow-up time was $10.2( \pm 3.4)$ years. The degree of dilation was grade I in $44(9.8 \%)$, grade II in 226 


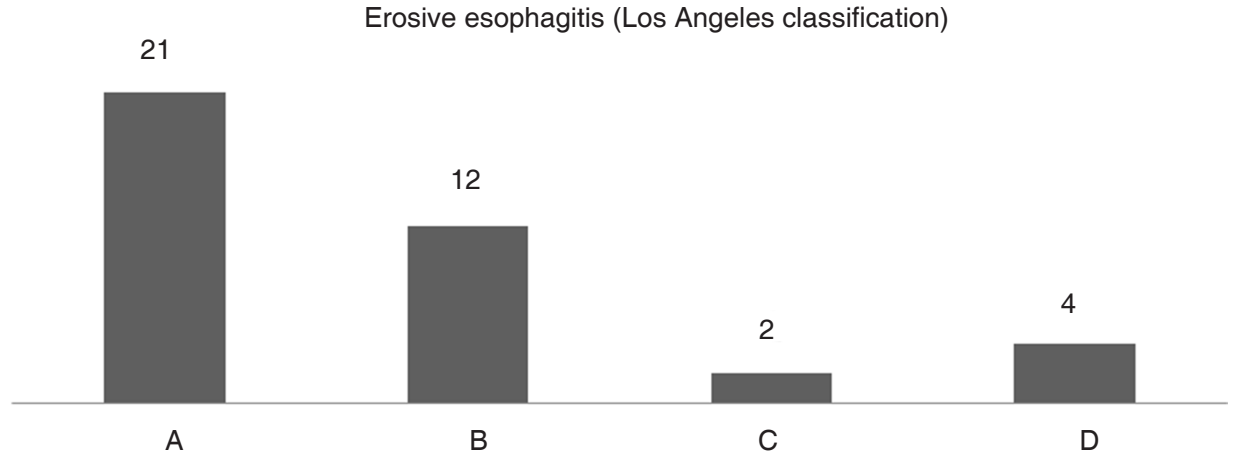

Figure 3: Number of patients with erosive esophagitis. Distribution according to Los Angeles classification

(50.7\%) and grade III in 175 (39.5\%). Thirty-nine (8.7\%) patients presented erosive esophagitis 5 years after surgery. In relation to the Los Angeles classification, 21 presented esophagitis A, 12 B, 2 C and 4 D [Figure 3]. Two patients with esophagitis Los Angeles $D$ also presented peptic sub stenosis, while the other 2 patients were identified with Barrett esophagus without atypia. With regard to the situation surrounding the fundoplication wrap, all remained detectable on endoscopic examination. However, 49 (11\%) were partially migrated to the thorax due to hiatal hernia. It was observed that $81(18 \%)$ patients had regular use of a proton pump inhibitor. However, it was noted that 42 patients were taking it per their cardiologist's prescription. These patients were chagasic and used various medications and presented dyspepsia and epigastric pain secondary to medication. The other 39 were precisely the patients who had erosion seen on endoscopy. Forty-one $(9.2 \%)$ patients had dysphagia and required some type of intervention to improve this condition: 37 had experienced clinical improvement with endoscopic dilation and 4 required reinterventions; 1 case of dysphagia being considered due to gastric migration and the other 3 due to myotomy fibrosis. We can see the dispersion of cases of dysphagia by time [Figure 4].

The odds ratio was calculated and a chi-square test conducted to determine the presence of erosive esophagitis in relation to the degree of dilatation, etiology, and valve migration [Table 1]. The same was done for the presence of dysphagia in relation to the degree of dilatation and migration of the wrap [Table 2] and finally to the presence of migration in relation to the degree of dilatation [Table 3].

It can be observed that when the fundoplication migrated there was a higher risk of developing erosive esophagitis $(P=0.047)$ and dysphagia $(P<0.001)$. There was no higher risk of migration when the esophagus was more dilated.

\section{DISCUSSION}

The need for an antireflux procedure after myotomy is no longer as controversial as it used to be. The presence of a myotomy in the distal esophagus counteracts the physiological function of the lower esophageal sphincter that prevents the gastric contents from going back to the esophagus. It is expected that gastro-esophageal reflux will occur and become more severe postoperatively ${ }^{[4-6]}$.

In a meta-analysis in 2009 , Campos et al. ${ }^{[7]}$ demonstrated an incidence of gastroesophageal reflux disease (GERD) among $31.5 \%$ of patients submitted to myotomy without fundoplication. It is very difficult to completely suppress gastroesophageal reflux after laparoscopic myotomy even when some antireflux procedure is associated. The rate of gastroesophageal reflux may range from $0 \%$ to $44 \%{ }^{[7]}$.

The type of anti-reflux procedure varies according to the circumferential extension of the fundoplication. The most frequently used are the $180^{\circ}$ anterior (Dor), $270^{\circ}$ (Toupet) and $360^{\circ}$ (Nissen). Despite the good control of reflux, the Nissen technique and its modifications are associated with a higher incidence of postoperative dysphagia (up to $75 \%$ ) and therefore it is not recommended for patients submitted to myotomy ${ }^{[8-10]}$. The choice of the best fundoplication post myotomy is still controversial. The Dor repair uses 2 lines of suture anchored in both borders of the myotomy. The coverage of the exposed submucosa in the myotomy with the Dor fundoplication allegedly has the advantage of blocking an eventual perforation of the myotomy. On the other hand, the Toupet fundoplication theoretically distances the edges of the myotomy, decreasing the risk of dysphagia recurrence ${ }^{[2,11,12]}$. The fundoplication performed in our procedure has some advantages of both. It covers the exposed submucosa because the gastric fundus is fixed at both edges of the myotomy and keeps contact to the anterior face. 
Table 1: Presence of erosive esophagitis in relation to the degree of dilatation, etiology and fundoplication status

\begin{tabular}{lccc}
\hline Characteristics & Odds ratio & $\mathbf{9 5 \%} \mathbf{C l}$ & $\boldsymbol{P}$ \\
\hline Dilatation & 1 & & \\
I & 0.58 & $(0.22-1.55)$ & 0.274 \\
II & 0.55 & $(0.2-1.53)$ & 0.246 \\
III & & & \\
Ethiology & 1 & & \\
$\quad$ Idiopathic & 1.85 & $(0.96-3.58)$ & 0.065 \\
Chagasic & & & \\
Fundoplication status & 1 & & \\
$\quad$ Intra-abdominal & 2.3 & $(1-5.33)$ & 0.047 \\
$\quad$ Wrap migration & & & \\
\hline
\end{tabular}

Additionally, it has a latero-posterior component with another suture line in the posterior part of the esophagus, resulting in $270^{\circ}$ of circumferential contact with the esophagus and thereby providing a reflux control similar to Toupet. Both anterior (Dor) and posterior (Toupet) are associated with good control of dysphagia after myotomy with results ranging between $77 \%$ and $96 \%{ }^{[13-15]}$. In a review involving more than 3,000 patients, dysphagia was resolved on average $89.3 \%$ of the time ${ }^{[7]}$. With our technique, we demonstrated a long-term dysphagia resolution rate of $91 \%$. In contrast, issues related to reflux are less reported after a Heller myotomy associated with a partial fundoplication.

Clinically, it is often difficult to accurately diagnosis gastro-esophageal reflux because of the reflux-like symptoms resulting from stasis and fermentation of esophageal contents retained in the esophageal lumen by ineffective or incomplete myotomy. One component believed to contribute to this is the severity of the esophageal dilatation. Once the obstacle in the distal esophagus is removed, the reflux of the gastric contents will find an atonic esophagus with literally no contractility capable of promoting esophageal clearance, relying mostly on gravity for emptying ${ }^{[16,17]}$.

The use of $\mathrm{pH}$ metry for the evaluation of reflux in patients with achalasia after myotomy with fundoplication is the main tool for quantitative analysis. However, due to the production of lactic acid secondary to the stasis of food and saliva in the distal esophagus the results can be misinterpreted. Tsiaoussis et al noted that up to $66 \%$ of reflux events may be secondary to this phenomenon. Additionally, they noted that the diameter of the esophageal lumen showed a positive correlation with a distal $\mathrm{pH}<4^{[18]}$.

Ortiz et al. ${ }^{[19]}$ evaluated $\mathrm{pH}$ results in 136 patients with a median 6-year follow-up after open myotomy; Toupet
Table 2: Presence of dysphagia in relation to the presence of esophagitis and fundoplication status

\begin{tabular}{lccc}
\hline Characteristics & Odds ratio & $\mathbf{9 5 \%} \mathbf{C l}$ & $\boldsymbol{P}$ \\
\hline Esophagitis & 1 & & \\
No esophagitis & 1.14 & $(0.38-3.38)$ & 0.814 \\
$\begin{array}{l}\text { Fundoplication status } \\
\quad \text { Intra-abdominal }\end{array}$ & 1 & & \\
$\quad$ Wrap migration & 3.54 & $(1.64-7.61)$ & $<0.001$ \\
\hline
\end{tabular}

Table 3: Presence of migration in relation to the degree of dilatation

\begin{tabular}{lccc}
\hline Dilatation & Odds ratio & $\mathbf{9 5 \%} \mathbf{C l}$ & $\boldsymbol{P}$ \\
\hline I & 1 & & \\
II & 1 & $(0.39-2.58)$ & 0.989 \\
III & 0.46 & $(0.16-1.32)$ & 0.143 \\
\hline
\end{tabular}

FP and abnormal pH results were found in 19 patients (14\%) overall, while abnormal acid exposure increased over the course of follow-up from $8.1 \%$ at 1 year to $18.5 \%$ at 5 years and $23.7 \%$ at 10 years.

We used, as a marker of reflux, the presence of erosive esophagitis because of the alteration in the $\mathrm{pH}$ metry of these patients, and also because it is not routine to perform this test on patients with megaesophagus under our care.

There is still no consensus as to the best fundoplication after this procedure. There are few controlled multi-centric studies because it is a rare disease. The only randomized, multi-institutional study comparing the 2 types of partial fundoplications showed gastroesophageal reflux in $41.7 \%$ of patients in the Dor group vs. $21 \%$ in the Toupet group. It was not possible to demonstrate a statistical difference due to sample size and follow-up ${ }^{[20]}$.

A meta-analysis of more than 2,500 patients showed an approximate $14.3 \%$ rate of reflux with anterior fundoplication and $15.8 \%$ with posterior and dysphagia indexes of $10 \%$ and $5.8 \%$, respectively ${ }^{[21]}$. We had with our antero-latero-posterior fundoplication a reflux rate of only $8.1 \%$ after more than 5 years of follow-up.

This meta-analysis study demonstrated that both partial fundoplications are associated with an equivalent control of GERD. However, anterior fundoplication is associated with higher reintervention rates for postoperative dysphagia compared with posterior fundoplication. The authors note that one of the reasons for this difference is that posterior fundoplication keeps the edges of the myotomy open and avoids potential adhesions that 


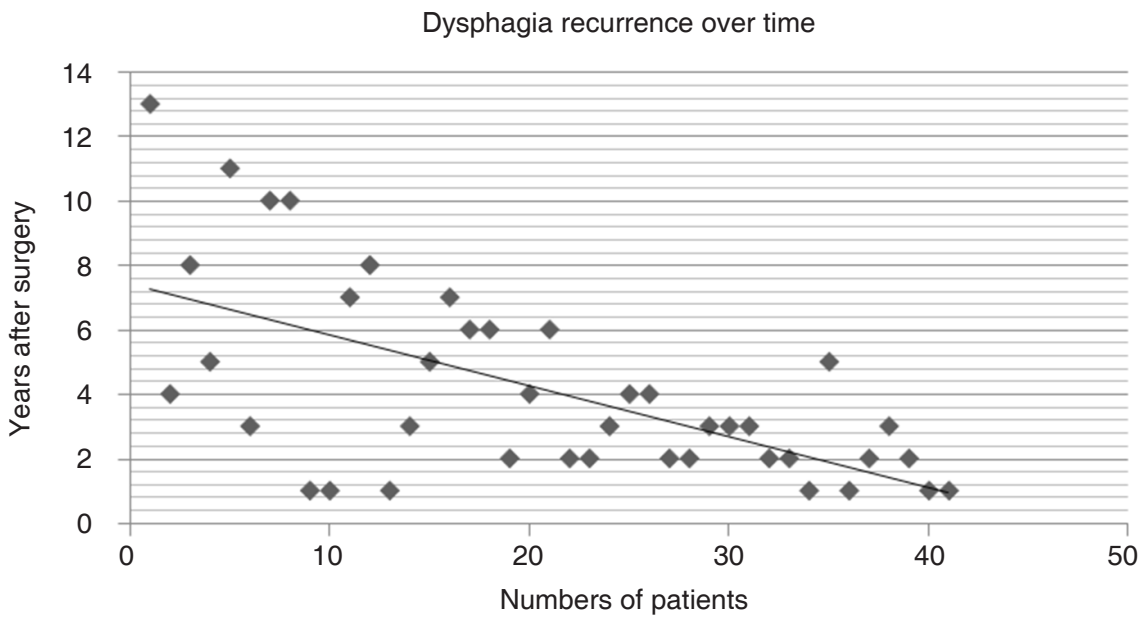

Figure 4: Dispersion of patients with recurrence of dysphagia over time

may develop between the myotomy and anterior fundoplication, resulting in fewer reinterventions for postoperative dysphagia ${ }^{[11,21,22]}$. Our fundoplication covers the exposed mucosa, and we only had 4 cases requiring reintervention. There are few studies evaluating endoscopic results. In a study comparing a Dor fundoplication group with a Toupet group, Katada et al. ${ }^{[23]}$ demonstrated that the pHmetry study was similar in both groups. However, both symptoms and endoscopic findings were different; reinforcing the importance of endoscopic and clinical findings for the evaluation of these cases.

Erosive esophagitis was found in $38.5 \%$ of the Toupet group and $8.8 \%$ of the Dor group, which was similar to the Toupet group in the same study ${ }^{[23]}$. Our study is not a comparative one, however we find better results with our fundoplication, even taking into account that more than half of our cases were erosive esophagitis Los Angeles A, which is a rather mild complication. In our procedure, we performed a dissection of the entire circumference of the hiatus to create a large segment of intra-abdominal esophagus and a large area for the myotomy. Simić et al. ${ }^{[2]]}$ found that Dor fundoplications in the setting of a complete hiatal dissection had a higher degree of abnormal esophageal acid exposure $(23.1 \%)$ than if a limited hiatal dissection was performed (8.5\%). However, when we performed a more extensive fundoplication than the Dor, we achieved a good success rate $(8.1 \%)$.

One factor not routinely reported in other studies is the migration of fundoplication to the thorax. Though we advocate the closure of the diaphragmatic hiatus after esophagus dissection, we nevertheless observed a $11 \%$ rate of hiatal herniation. This event correlated with the presence of reflux esophagitis $(P=0.047)$ and also with dysphagia $(P<0.001)$. Gastric migrations through the hiatus have a tendency to to decrease the function of the fundoplication due to the negative pressure in the thorax. Perhaps this alteration of the anatomy also allows the edges of the myotomy to approach, and may be related to the difficulty of passage of the bolus due to the ensuing deformities by the hiatal hernia itself. We had 3 cases in which the reintervention was due to myotomy fibrosis and one where the deformity of the hernia clearly originated with dysphagia.

First, we thought that it was important to classify the etiology of achalasia as chagasic or idiopathic because Chagas disease is very common in Brazil. However, we observed that these two groups of patients behave in a similar manner during the treatment, with no difference in outcome. Our study has the limitation of being a retrospective, non-comparative study. Because only medical records were obtained, it was not possible to apply any specific questionnaire regarding reflux or dysphagia. Only information reported by the patient was used and the severity of the reflux or dysphagia was unable to be quantified. The use of a proton pump inhibitor for reasons other than reflux symptoms may also be a bias in the number of patients with endoscopic alterations. However, this number was small and patients had no reported reflux symptoms in their history.

In conclusion, we have demonstrated that laparoscopy myotomy postero-latero-anterior fundoplication (Heller-Pinotti) has a good long-term outcome in relation to dysphagia and in terms of reflux prevention. Furthermore, it could produce better results than other partial fundoplications, however it requires both a prospective and comparative study. 


\section{DECLARATIONS}

\section{Authors' contributions}

Concept and design: E.T. Bianchi, R.A.A. Sallum, S.

Szachnowicz

Manuscript preparation: E.T. Bianchi, R.A.A. Sallum, J.R.M. da Rocha

Data and statistical analysis: E.T. Bianchi, A.F. Duarte Manuscript editing: S. Szachnowicz, F.C.B.C. Seguro, A.F. Duarte

Literature search: E.T. Bianchi, F.C.B.C. Seguro, A.F. Duarte

Manuscript review: R.A.A. Sallum, J.R.M. da Rocha, I. Cecconello

\section{Financial support and sponsorship None.}

\section{Conflicts of interest}

There are no conflicts of interest.

\section{Patient consent \\ Patient informed consents were obtained before the operation, as in all procedures.}

\section{Ethics approval}

This retrospective data collection was approved by the Ethical Committee of our hospital.

\section{REFERENCES}

1. St Peter SD, Swain JM. Achalasia: a comprehensive review. Surg Laparosc Endosc Percutan Tech 2003;13:227-40.

2. Patti MG, Herbella FA. Fundoplication after laparoscopic Heller myotomy for esophageal achalasia: what type? J Gastrointest Surg 2010;14:1453-8.

3. Pinotti H, Gama-Rodrigues J, Ellenbogen G, Raia A. Nova técnica no tratamento cirúrgico do megaesôfago. Esofago-cardiomiotomia associada com esofago - fundogastropexia. Rev Goiana Med 1974;20:1-13. (in Portuguese)

4. Falkenback D, Johansson J, Oberg S, Kjellin A, Wenner J, Zilling T, Johnsson F, Von Holstein CS, Walther B. Heller's esophagomyotomy with or without a 360 degrees floppy Nissen fundoplication for achalasia. Long-term results from a prospective randomized study. Dis Esophagus 2003;16:284-90.

5. Kjellin AP, Granqvist S, Ramel S, Thor KB. Laparoscopic myotomy without fundoplication in patients with achalasia. Eur J Surg 1999;165:1162-6.

6. Richards WO, Torquati A, Holzman MD, Khaitan L, Byrne D, Lutfi R, Sharp KW. Heller myotomy versus Heller myotomy with Dor fundoplication for achalasia: a prospective randomized double-blind clinical trial. Ann Surg 2004;240:405-12; discussion 412-5.

7. Campos GM, Vittinghoff E, Rabl C, Takata M, Gadenstätter M, Lin F, Ciovica R. Endoscopic and surgical treatments for achalasia: a systematic review and meta-analysis. Ann Surg 2009;249:45-57.
8. Topart P, Deschamps C, Taillefer R, Duranceau A. Long-term effect of total fundoplication on the myotomized esophagus. Ann Thorac Surg 1992;54:1046-51; discussion 1051-2.

9. Chen LQ, Chughtai T, Sideris L, Nastos D, Taillefer R, Ferraro P, Duranceau A. Long-term effects of myotomy and partial fundoplication for esophageal achalasia. Dis Esophagus 2002;15:171-9.

10. Rebecchi F, Giaccone C, Farinella E, Campaci R, Morino M Randomized controlled trial of laparoscopic Heller myotomy plus Dor fundoplication versus Nissen fundoplication for achalasia: long-term results. Ann Surg 2008;248:1023-30.

11. Hunter JG, Trus TL, Branum GD, Waring JP. Laparoscopic Heller myotomy and fundoplication for achalasia. Ann Surg 1997;225:65564; discussion 664-5.

12. Oelschlager BK, Chang L, Pellegrini CA. Improved outcome after extended gastric myotomy for achalasia. Arch Surg 2003;138:490-5; discussion 495-7.

13. Patti MG, Molena D, Fisichella PM, Whang K, Yamada H, Perretta S, Way LW. Laparoscopic Heller myotomy and Dor fundoplication for achalasia: analysis of successes and failures. Arch Surg 2001;136:870-

14. Khajanchee YS, Kanneganti S, Leatherwood AE, Hansen PD Swanström LL. Laparoscopic Heller myotomy with Toupet fundoplication: outcomes predictors in 121 consecutive patients. Arch Surg 2005;140:827-33; discussion 833-4.

15. Zaninotto G, Costantini M, Rizzetto C, Zanatta L, Guirroli E, Portale G, Nicoletti L, Cavallin F, Battaglia G, Ruol A, Ancona E. Four hundred laparoscopic myotomies for esophageal achalasia: a single centre experience. Ann Surg 2008;248:986-93.

16. Malthaner RA, Tood TR, Miller L, Pearson FG. Long-term results in surgically managed esophageal achalasia. Ann Thorac Surg 1994;58:1343-6; discussion 1346-7.

17. Ellis FH, Crozier RE, Gibb SP. Reoperative achalasia surgery. $J$ Thorac Cardiovasc Surg 1986;92:859-65.

18. Tsiaoussis J, Pechlivanides G, Gouvas N, Athanasakis E, Zervakis N, Manitides A, Xynos E. Patterns of esophageal acid exposure after laparoscopic Heller's myotomy and Dor's fundoplication for esophageal achalasia. Surg Endosc 2008;22:1493-9.

19. Ortiz A, de Haro LF, Parrilla P, Lage A, Perez D, Munitiz V, Ruiz D, Molina J. Very long-term objective evaluation of heller myotomy plus posterior partial fundoplication in patients with achalasia of the cardia. Ann Surg 2008;247:258-64.

20. Rawlings A, Soper NJ, Oelschlager B, Swanstrom L, Matthews BD Pellegrini C, Pierce RA, Pryor A, Martin V, Frisella MM, Cassera M, Brunt LM. Laparoscopic Dor versus Toupet fundoplication following Heller myotomy for achalasia: results of a multicenter, prospective, randomized-controlled trial. Surg Endosc 2012;26:18-26.

21. Kurian AA, Bhayani N, Sharata A, Reavis K, Dunst CM, Swanström LL. Partial anterior vs partial posterior fundoplication following transabdominal esophagocardiomyotomy for achalasia of the esophagus: meta-regression of objective postoperative gastroesophageal reflux and dysphagia. JAMA Surg 2013;148:85-90.

22. Vogt D, Curet M, Pitcher D, Josloff R, Milne RL, Zucker K. Successful treatment of esophageal achalasia with laparoscopic Heller myotomy and Toupet fundoplication. Am J Surg 1997;174:709-14.

23. Katada N, Sakuramoto S, Yamashita K, Hosoda K, Shibata T, Moriya H, Kikuchi S, Watanabe M. Comparison of the Heller-Toupet procedure with the Heller-Dor procedure in patients who underwent laparoscopic surgery for achalasia. Surg Today 2014;44:732-9.

24. Simić AP, Radovanović NS, Skrobić OM, Raznatović ZJ, Pesko PM. Significance of limited hiatal dissection in surgery for achalasia. $J$ Gastrointest Surg 2010;14:587-93. 